Maxwell Peprah Opoku*, Wisdom Kwadwo Mprah, Judith Mckenzie, Bernard Nsaidzedze Sakah and Eric Badu

\title{
Lives of persons with disabilities in Cameroon after CRPD: voices of persons with disabilities in the Buea Municipality in Cameroon
}

DOI 10.1515/ijdhd-2016-0009

Received February 6, 2016; accepted March 8, 2016

\begin{abstract}
Introduction: The Convention on the Rights of Persons with Disabilities (CRPD) has been touted as a major breakthrough towards achieving equal rights for persons with disabilities. The promulgation of the convention provided clear guidelines for signatory countries to revise their legislation as well as to formulate policies that will take into consideration the needs of persons with disabilities. As Cameroon is a signatory to the convention, it is expected that disability-friendly policies have been implemented to enhance the living conditions of persons with disabilities. This study examined, from the perspectives of participants, the life experiences of persons with disabilities in the Buea Municipality 7 years after Cameroon signed the CRPD.

Methods: The study adopted a qualitative method, involving focus-group discussions with 36 participants from three disability groups: hearing impaired, visually impaired, and physically impaired.

Findings: The study found that persons with disabilities in the Buea Municipality faced many challenges in their daily endeavors. These challenges are a result of a lack of inclusive policies, leading to their exclusion from social and economic activities such as education, employment, and healthcare.
\end{abstract}

\footnotetext{
*Corresponding author: Maxwell Peprah Opoku, Centre for Disability Rehabilitation Studies, Kwame Nkrumah University of Science and Technology, Kumasi, Ghana,

E-mail: abizep4@yahoo.com

Wisdom Kwadwo Mprah: Centre for Disability Rehabilitation Studies, Kwame Nkrumah University of Science and Technology, Kumasi, Ghana

Judith Mckenzie: Faculty of Health Sciences, University of Cape Town, Cape Town, South Africa

Bernard Nsaidzedze Sakah: Pan African University Institute of Humanities, Governance and Social Sciences, Soa-Yaounde, Cameroon Eric Badu: Centre for Disability Rehabilitation Studies, Department of Community Health, Kumasi, Ghana
}

Conclusions: Although the study is limited in scope, the findings suggest that persons with disabilities in the Buea Municipality were yet to benefit from the CRPD. It is, therefore, suggested that the government of Cameroon should formulate inclusive policies to address the numerous challenges facing persons with disabilities in the Buea Municipality.

Keywords: accessibility; Cameroon; discrimination; persons with disabilities; poverty.

\section{Introduction}

There is an estimated one billion people living with some form of disability worldwide, of which approximately $80 \%$ live in developing countries [1, 2]. Studies indicate that a majority of persons with disabilities experience social marginalization and deprivation, and are excluded from many socioeconomic activities [3-5]. For example, it has been indicated that, on an average, and as a group, persons with disabilities are more likely to experience adverse socioeconomic conditions such as lower educational attainment, poorer health outcomes, lower employment, and higher rates of poverty than persons without disabilities [2, 6-8]. As a consequence, persons with disabilities are more likely to have limited access to safe housing, food, and healthcare $[4,7,9]$.

Additionally, while persons with disabilities are generally disadvantaged economically $[2,7]$, they are also more likely to incur additional costs arising from their disability $[10,11]$. These extra expenses may include the need for specialized medical care, acquisition of assistive devices, or the need for personal support and assistance $[3,9]$. Furthermore, as persons with disabilities generally require more resources and support to achieve the same outcomes as persons without disabilities, families with relatives with disabilities are more likely to experience harsher economic conditions $[2,6,8,9,12]$. 
Although evidence on the level of poverty among persons with disabilities is limited and inconclusiveWHwwWGHIW, the available data indicate that persons with disabilities are worse off compared to their peers without disabilities in terms of access to employment, education, and healthcare in several developing countries such as those in Asia and Africa [2, 12-16]. For example, studies have identified lower employment outcomes among persons with disabilities in Namibia [13], Zambia [14], Mozambique [17], India [18], and Uganda [19]. Similarly, in a 14-household survey in 13 developing countries in Africa, Latin America, and Southeast Asia, Filmer [7] discovered that children with disabilities between the ages of 6 and 17 years were less likely to enroll in school. Studies in Uganda [19], Malawi [20], and Rwanda [21] have also found lower educational attainment among adults with disabilities.

Data on the persons with disabilities in Cameroon are limited but the little available data suggest that the situation is not different from other countries in Africa. For instance, studies conducted by the International Centre for Evidence in Disability (ICED) [22] and Cockburn, Cleaver, and Benuh [23] revealed that persons with disabilities in Cameroon faced serious barriers to education, employment, housing, and healthcare. For example, the ICED [22] found that adults with disabilities in Cameroon were 3.7 times less likely to work due to an inaccessible physical environment. It was also found that knowledge of rehabilitation and assistive devices among persons with disabilities and their families was low, thus limiting their utilization of these services.

Conditions in which persons with disabilities live have attracted attention within the international development community and this has led to a series of activities aimed at addressing their concerns. One of the major strides in this direction is the promulgation of the United Nations Convention on the Rights of Persons with Disabilities (CRPD) and its optional protocols, adopted on December 132006 [24]. Given the level of exclusion and human rights violations of persons with disabilities, the coming into force of the CRPD was seen as a major breakthrough towards achieving equal rights for persons with disabilities and also ensuring that their inherent human dignity is respected $[25,26]$. By shifting attention from the medical or charity perspective to a human rights-based perspective, the CRPD opened up opportunities for persons with disabilities to have access to and participate in decisions on all issues that affect their lives, and also offered them an avenue to seek redress for the violations of their rights $[25,27]$.

With the coming into force of the CRPD, it is expected that signatory countries will revise or formulate disability-friendly legislations and policies to ensure the full participation of persons with disabilities in all activities on equal basis as other members of their community [24]. However, implementation of the convention in many countries, especially those in the developing world, has been characterized by many challenges. A major setback in the implementation of the convention is the lack of human and financial resources on the part of Disabled People's Organizations (DPOs) and governments in developing countries to implement the convention. In addition, and more importantly, most governments, for example, in Africa, have demonstrated little commitment to implement the convention [28]. As such, persons with disabilities in many developing countries are yet to feel the effect of the CRPD as issues such as poverty, social exclusion, and human rights violations are still widespread in many countries [29].

Cameroon registered as a signatory to the CRPD and its optional protocols in 2008. It is, therefore, expected that steps have been taken by the government to implement various provisions in the CRPD to mainstream the concerns of persons with disabilities in the country. However, it appears that little has been done in terms of implementation of the CRPD, as indicated by studies conducted by ICED [22] and Cockburn, Cleaver, and Benuh [23]. This study was conducted to further explore the issues. It was guided by the following questions: (1) what barriers do persons with disabilities encounter participating in mainstream activities in the Buea Municipality, and (2) what are the coping strategies to overcome these challenges? In addressing these questions, this study provided insights and understanding into the extent to which the CRPD has been implemented in the Buea Municipality of Cameroon from the perspectives of persons with disabilities.

\section{Materials and methods}

\section{Study design}

The study was qualitative and utilized focus group discussions to collect data from participants. The group discussions presented an opportunity for the participants to express their opinions on their life experiences in the Buea Municipality, i.e. it allowed participants to freely express their thoughts on the challenges they encountered daily and how they coped with these challenges.

\section{Background on Cameroon}

Cameroon is in Central Africa, located north of the Gulf of Guinea. It shares borders with Nigeria to the west, Chad to the northeast, the 
Central African Republic to the east, and Equatorial Guinea, Gabon, and Congo to the south. The population of Cameroon is estimated at 23,130,708 people based on a 2012 World Bank statistic. According to the Human Development Report of 2013, over 50\% of the population in Cameroon lived below the poverty line. The reported further stated that women and youth were largely affected. According to McSweeney et al. [30], the population of persons with disabilities in Cameroon is a little over 2 million, using the WHO 10\% estimates.

\section{Study area}

The study was conducted in Buea, a municipal council and also the capital of the Southwest Region of Cameroon. Buea is one of the areas in Cameroon with a high rate of literacy, as between $60 \%$ and $75 \%$ of the youth are educated. However, it is believed that $40 \%$ of the people in the municipality have no access to healthcare while $60 \%$ are unable to afford it. The life expectancy in the area is 50 years. It is one of the fastest growing towns in Cameroon with a mixed cosmopolitan setting and is a moderate economy with the agricultural, administrative, business, tourism, and financial sectors being the main economic activities of the town [31].

\section{Population and sample}

The target population for the study was persons with disabilities in the Buea Municipality. Participants were selected from the visually, physically, and hearing impaired. These groups had well-organized associations in the area, so it was easy to target them using the leaders of the various associations.

The study adopted purposive random sampling to recruit 12 participants from each disability group. We purposely selected participants who were considered knowledgeable on the issue under investigation. As the study explored the life experiences of persons with disabilities with respect to the implementation of the CRPD in Buea, it was appropriate to purposively recruit persons who had some knowledge on the CRPD and could provide information on issues affecting the persons with disabilities in the study area. Persons selected were opinion leaders and included past and current executives of the disability groups and persons who were performing some leadership roles in the area.

In all, 36 participants took part in three different group discussions. Out of the total participants, the majority were females (55.6\%), and nearly $40 \%$ were between 21 and 30 years, while $8.3 \%$ were above 50 years. The mean age of the participants was 30.2 years. On employment, more than $40 \%$ of the participants were unemployed, while only $10 \%$ were employed in the public sector. In terms of education, close to $50 \%$ of the participants had no formal education compared to $28.2 \%$ who had primary education. Also, less than half $(36.1 \%)$ mentioned that they were catering for themselves while the remaining were depending on non-governmental organizations (30.6\%) and family members (33.3\%). Table 1 below summarizes the demographic characteristics of participants.

\section{Method of data collection}

Three different group discussions were organized for the three disability groups (hearing, visually, and physically impaired).
Table 1: Demographic characteristics of participants.

\begin{tabular}{lrr}
\hline Variable & Frequency & Percentage, \% \\
\hline Age & & \\
$\leq 20$ & 8 & 22.2 \\
$21-30$ & 14 & 38.9 \\
$31-40$ & 6 & 16.7 \\
$41-50$ & 5 & 13.9 \\
$>50$ & 3 & 8.3 \\
Mean & 30.2 & \\
Education & & \\
No formal education & 17 & 47.2 \\
Primary & 8 & 22.2 \\
Vocational & 11 & 30.6 \\
Employment & & \\
Government/civil servant & 3 & 8.3 \\
Trading & 5 & 13.9 \\
Farming & 2 & 19.6 \\
Apprenticeship & 7 & 41.7 \\
None & 15 & 11.1 \\
Other & 4 & 33.3 \\
Means of survival & & 36.1 \\
Family & 12 & 30.6 \\
Self & 13 & \\
NGOs & 11 & \\
\hline & & \\
& & \\
& &
\end{tabular}

A semi-structured focus group guide was used to guide the group discussions. The researchers discussed the guide with the leadership of [DPOs for their input before data collection. The broad issues that were discussed included selected provisions in the CRPD such as equality and non-discrimination, awareness creation, accessibility to essential services, the extent to which the state had implemented provisions in the CRPD, as well as the daily-life experiences of persons with disabilities. Ground rules were laid before the discussions commenced to enhance equal participation among participants. This included advising participants to respect the opinions of others and to draw the attention of the moderator by raising their hands before speaking. The discussions were audio recorded with permission from the participants. With the exception of deaf participants, who used sign language, all participants spoke Pidgin English, which is the main language spoken by the people in Buea. One of the researchers fluent in Pidgin English led the discussions. For the deaf participants, an interpreter translated the sign language by voicing into an audio recorder.

\section{Data management and analysis}

The audio-recorded discussions were transcribed verbatim by the researchers. The researchers listened to each audio recording several times before transcribing. After the transcription, the transcripts for each group were shared among the researchers to read through and to reconcile differences in the transcription. Based on the research questions, we developed a coding system which involved assigning different alphabetical codes to each of the groups and numerical codes to each research question. As we read through the transcripts, relevant statements and concepts related to our research questions were assigned numerical codes representing the research questions 
and alphabetical codes indicating the group that discussed it. This enabled us to differentiate themes from the three groups. The researchers then met and discussed the themes. Afterwards, similar themes, using the codes, were grouped together to form the main sections of the final report.

\section{Results}

\section{Perceptions about disability}

Participants discussed perceptions that people in the study area held about disability. Almost all participants agreed that people in the study area were holding negative perceptions about disability. According to the participants, most people thought disability was a curse arising out of the evil deeds of their parents or family members. Due to this perception, people did not want to support or associate with persons with disabilities.

\begin{abstract}
They think disability is a curse so wherever I go they don't want to come close to me. Even if I need help, no one wants to come and help me because they think my grandfather cursed my mother. That is the explanation they give for my condition [Physically impaired 2]
\end{abstract}

Everyone has abandoned me because they are saying my father stole someone's goat and the person cursed him. I know it's not true because doctors told me not to listen to those comments from people. It hurts when I hear that I have been cursed. Anytime I offend someone that's what they tell me and it makes me cry a lot when I'm alone [Visually impaired 11]

I have heard it so many times that there is a curse in my family that is why I'm blind. I'm always home alone because nobody wants to be with someone who is cursed. There are people I expect to know better, but they all think same way [Visually impaired 3]

Another common misconception cited by the participants is that people thought the gods saw that they (persons with disabilities) were potential troublemakers who would cause a lot of problems for their families and communities. Therefore, they were disabled by the gods to reduce their potency to cause trouble. One participant explained:

Disabled persons are usually blamed for negative actions that occur in their communities. People still believe that we are potential evil doers. That is why the gods changed our destiny and made us this way. The gods saw that we would cause problems so they had to stop it from happening [Physically impaired 1]

Participants also expressed their displeasure about being gazed at wherever they went by people in the community, thus, making them uncomfortable and restricting their movement. Two physically impaired participants narrated their experiences in the quotes below.

I don't go out often because people look at me too much. I get a lot of attention since I crawl on the floor. Whenever I want to cross the road almost everyone stares at me. It is embarrassing so I don't go out [Physically impaired 8]

It is hard to live here as a disabled. Everyone will stop whatever they are doing and stare, therefore I can neither go to church nor go for programmes if not meeting like this. So many people will be looking at me and gossiping. Even children will be following me and watching how I'm 'walking' with my hands. These kinds of things keep me home [Physically impaired 2]

The perception that persons with disabilities are worthless and incapable of doing anything to support their families and communities was cited as widespread among the people in the area. Several participants expressed their discontent about being reduced to worthless objects incapable of doing anything beneficial in their lives. Three participants shared their experiences:

It is very sad that our own people don't believe in us. They see us as worthless persons who can't support the family in anyway. I have suffered this all my life and I'm now used to it. It hurts my soul to hear people say 'what can he do?' [Hearing impaired 1]

I have suffered a lot in my own home. They doubt what I can do and always don't see me as a valuable person. I have fought this all my life. I have to endure it but I know it is wrong. We are also humans, and there is a lot that we can do if given the chance or opportunity. We can do something but we have not been given the opportunity [Physically impaired 7]

Persons with disabilities in this community are suffering since people don't trust our abilities. If you compete for a position with non-disabled, the non-disabled will be chosen because they believe he can better fit for the job or position. They don't value us at all [Visually impaired 4]

\section{Rejection by family members}

Article 5 of the CRPD admonishes states to work towards attaining a just and equal society where individuals would not be discriminated against based on their disability. However, responses from participants indicated that persons with disabilities in the study area encountered discrimination and social exclusion. For example, according to participants, they were not considered as equal members of their families and were often excluded from decision-making because they were unable to contribute to the maintenance of the family.

They don't call me whenever the family is making a decision. Even when somebody dies in the family, they don't invite me. They are 
my family and I often expect them to involve me in whatever they do but that is never the case. They often call everyone except me [Visually impaired 6]

I'm not working so they don't count me as an equal member of the family. They only invite those who are working whenever they are taking decisions in the family. I stay in the family house but they have never discussed or asked about my opinion over issues [Hearing impaired 4]

Since I became disabled, I can't work so people don't value my opinion anymore. My own wife and children don't ask or discuss issues with me. She is the one working and taking care of the family so the children listen to her more and not me [Physically impaired 9]

Participants also mentioned that they did not receive any support from their families. For example, some participants claimed that while their siblings without disabilities received a lot of support from their parents to attend school, they (persons with disabilities) had to struggle to raise funds for their education and healthcare.

My father took all his children to school except me. I now understand he left me home because of my disability. This shouldn't be the case. The fact that I'm disabled doesn't mean I can't learn but that is how I was treated [Visually impaired 3]

I don't get any support from my family ever since I started going to school. I beg for money during holidays to support my education. My church too has been helpful as they give me money when I'm in need. All my brothers are in school and they are being supported by my family but they don't want to help me [Hearing impaired 7]

When I tell my people that I'm sick, no one is willing to give me money to go to the hospital. I struggle before strangers give me something to support myself. I need assistance from my family but they behave as if I'm not human [Visually impaired 7]

Some families even went to the extent of ejecting their relatives from their homes due to their disability. Two participants shared their experiences:

My father built a house for his children but my elder brother chased me out of the house. I stay in an old kiosk. Whenever I go home to greet them and tell them my needs, they don't want to listen to me. Everything has been bad for me since my father died [Physically impaired 4]

I have no one to help me. My room was rented out to someone because my father said he needed money. I'm now staying in the mission house because my pastor likes me and decided to help me. They've given me what my family couldn't give me [Visually impaired 5]

Although the above comments appear to be exaggerated, it is not unexpected for families to abandon or dissociate themselves from their relatives with disabilities because of the stigma and negative perceptions associated with disability in many African societies.

\section{Access to services}

Responses from all the groups indicated that persons with disabilities in the area had limited access to basic services such as education, employment, and healthcare.

\section{Education}

As their demographic characteristics indicated, most of the participants had low formal education. While some of the participants attributed their inability to attain higher education to poverty, others attributed it to the absence of educational facilities that support the needs of children with disabilities. For example, five participants claimed that their parents did not enroll them in school because they did not have the financial resources to invest in their education. The following quotes highlighted this viewpoint.

One's socioeconomic background will determine one's ability to have access to education. I was in the village and my parents didn't have the money to pay for my transportation every day. I had to drop out of school because of poverty [Physically impaired 1]

Disability is not the problem but parents can't provide us with the sponsorship we need to be in school. I couldn't buy books, tuition fees and materials needed for school. I was forced to stop school due to financial problems [Hearing Impaired 5]

My father was only a farmer and he had so many children to cater for so there wasn't any money to invest in my education. I knew he would have done it if the means was there. He wasn't getting much from his job coupled with many responsibilities too [Visually impaired 11]

These quotes suggested that not everyone in the study area had a negative attitude towards persons with disabilities. However, most [21] of the participants blamed the inability of persons with disabilities to attain higher education mainly on the lack of educational facilities for children with disabilities. According to these participants, there were no specials schools in the area and the general schools would not accept them. Two participants narrated their experiences:

There is no deaf school in this community. The government has not provided any school for us. We don't get admission to public schools because they say those schools aren't meant for us. It is difficult to go to school as a disabled in this town [Hearing impaired 4] 
Our government has not built schools for hearing impaired in this community. Going to school is not easy because the schools are not there. I was in a public school but my class teacher told me to stay home since going to school won't help me in life. I knew it was difficult for them to teach me [hearing impaired 1]

Since the public schools would not enroll children with disabilities, the only option available for those who wanted to go to school was to enroll in schools established by private persons and NGOs, which are very expensive and very few families can afford. For instance, one visually impaired participant said she dropped out of school due to the inability of her parents to support her financially in a private school. Apart from the cost, participants who attended private schools mentioned that the schools were not well resourced to handle the needs of persons with disabilities and this adversely affected their academic performance. In particular, the hearing-impaired participants claimed that a majority of teachers were untrained and were not fluent in sign language, making it difficult for the teachers to teach them. Two participants summarized their thoughts as follows:

The teachers learn the sign language from us. All our teachers are untrained but they are doing their best. It's not easy to pass but we keep working hard. They are not able to explain things to us clearly because they were not trained to teach deaf [Hearing impaired 9]

Our teachers struggle to teach during classes. They can't sign most of the things to us so at times we find it difficult to understand them. Every year, most of the students fail because we don't have the right teachers at our school [Hearing impaired 7].

Access to education is an important step towards economic empowerment for persons with disabilities as it will create opportunities for their inclusion in socioeconomic activities. However, their limited access to education means that they would have limited access to economic and social opportunities.

\section{Access to employment}

Almost all the participants complained of limited employment opportunities for persons with disabilities in the area. Persons with disabilities were unable to access jobs opportunities because of their low formal education, which made it difficult for them to compete for jobs. Some participants commented:

Getting jobs require certificates without which you can't have it. I don't have any certificate so there is no way I'm going to get a job. I didn't go to school and no one is going to give any job. Although I can work but without a certificate, I have no hope of getting a job [Hearing impaired 2]

Jobs are limited in this country so being a disabled without any qualification means that you can't get any job. Wherever you go, they will ask for certificate which most of us don't have. Not even the government will give us jobs [Visually impaired 4].

Without the necessary qualification and skills, persons with disabilities had to settle on menial jobs, petty trading, begging, and relying on others for a living. Four participants commented:

I have no hope of getting any job in this country so I cope by selling a few things by the roadside to take care of my family. My church gave me some money to start doing something because I was always going to the mission house to beg for money to buy food. It is not much but I'm happy that I'm no more begging [Physically impaired 10]

Someone has given me some few things to sell so that I can get something to eat with my children. I don't get much profit but it is better than not having anything to do while the children suffer. I just hope that I will be able to save some money and expand it [Hearing impaired 6]

I always beg people for food because I can't work like any other person since I have no hands but I can do well in other fields if I have skills and training. Assistance from people is my only means of survival for now [Physically impaired 12]

I'm always home because I can't find any job to do. My mother and other family members have been providing me with food and few things I need. I couldn't go to school and I have not learnt any trade that is why I have not been able to get a job. I hope to learn some trade and start something on my own [Visually impaired]

\section{Healthcare}

It was revealed during the discussions that several factors limited access to healthcare for persons with disabilities in the area. However, the cost of seeking healthcare was the major factor inhibiting access as many of them were unemployed.

Hospital bills are too expensive for us. We pay for treatment like any other persons but I have seen cases where disabled are treated even when their money gets finished after which they may be given a menial job at the hospital from where they will completely pay their bills, But not all disabled benefit from this [hearing impaired 11]

I was supposed to see a physiotherapist every month but I have no money to go. The doctors are there to assist us but there is no money. Maybe my condition would have improved by now but the money is not there. Going to hospitals is not free [Physically impaired 1]. 
Without jobs, it was obvious that persons with disabilities would have difficult access to healthcare unless they were supported. Another factor that hindered access to healthcare was inaccessible healthcare facilities. Some participants, especially the physically and visually impaired, mentioned that the physical environment in the hospitals was inaccessible and limited their access to medical care.

I can't go to the hospital without someone guiding me. If I'm sick and there is no one around to take me, I can't go alone. There was a time I fell down when I went alone, so I decided never to go on my own again [Visually impaired 7]

The hospital wasn't built for us. It's hard to move with my wheelchair so I have to pay someone to carry me whenever I'm going for treatment. If I'm not very sick, I don't go to the hospital. I only send someone to buy me drugs from the road. I know it is not good but that is the best since I can't go and pay someone to carry me [Physically impaired 3]

Communication barriers hindered access to the hearing and the visually impaired because information at the health care centers was not in accessible formats such as sign language and Braille. The following comments illustrate the above:

The hospital beds are high for me to climb and they have not made any arrangement to protect us from getting hurt. I can't read anything. I wish I would be able to know my health records by going through my files but it is not braille so I can't read myself [Visually impaired 5].

It is hard to communicate with doctors and nurses whenever I'm sick. They don't know the sign language so it makes it difficult to tell them my problem. At times there is something that I need but there is no one to talk due to communication problem [Hearing impaired 2]

It can be seen from the above narratives that persons with disabilities in the area encountered many challenges in their daily lives because their needs had not been mainstreamed.

\section{Discussion}

As the study targeted only a small sample of persons with disabilities in the Buea Municipality, findings of the study should be interpreted with caution. Nevertheless, findings offer insights into the living condition of persons with disabilities living in the Buea Municipality in Cameroon, and provide some information on the extent to which the CRPD has been implemented by the Cameroonian government 7 years after being a signatory.
The CRPD requires that signatory countries implement disability-friendly policies so that persons with disabilities can exercise their rights on an equal basis as their peers without disabilities. The CRPD also has mechanisms for promoting, protecting, and monitoring the implementation of its provisions [25-27]. As Cameroon is a signatory to the CRPD, it suggests that, in principle, it has agreed to implement provisions in the CRPD and also ensure that there are monitoring mechanisms to promote and protect the rights of persons with disabilities wherever they are. It is, therefore, expected that some structures would have been put in place to ensure that persons with disabilities in the Buea Municipality are able to exercise their rights as equal members of their communities. For example, there should have been steps to remove barriers to education, employment, and healthcare for persons with disabilities and to guarantee that their human dignity is respected and protected.

However, findings of the study suggest that little has been done in terms of implementation of the CRPD in the study area. There seemed to be no policy aimed at promoting and protecting the rights of persons with disabilities and to ensure that their human dignity, as provided for in the CRPD, is upheld. For example, the finding that negative attitude towards persons with disabilities was widespread in the area and physical barriers were hindering access to social and economic activities, suggests that not much has been done to implement the CRPD. These findings suggest lack of commitment on the part of government to prioritize issues concerning persons with disabilities and also corroborate studies indicating that issues affecting persons with disabilities have not been a priority in many countries, especially those in developing $[28,29]$. According to Ito [29], persons with disabilities in many developing countries are yet to benefit from the CRPD and issues such as poverty, social exclusion, human rights violations, inaccessible physical environments, and negative perceptions about disability are still common phenomena. Although little is known about the situation of persons with disabilities in Cameroon in general, the findings are suggestive and in agreement with previous studies conducted by ICED [22] and Cockburn, Cleaver, and Benuh [23]. These studies have found that persons with disabilities in parts of Cameroon have difficulty accessing education, employment, and healthcare.

\section{Implications for policy making}

The findings of the study have implications for designing advocacy strategies and formulating inclusive policies 
for persons with disabilities in the Buea Municipality and Cameroon in general. The finding that negative attitude is a major challenge for persons with disabilities points to the need to sensitize people, including policymakers, on disability issues so that the rights of persons with disabilities will be recognized and accepted. There is, therefore, the need for intensive public awareness campaigns on the rights of persons with disabilities in the area. There should also be affirmative action to mainstream disability issues. For instance, to promote the participation of persons with disabilities in economic activities, job quotas in both private and public sectors could be introduced to create more opportunities for persons with disabilities. In addition, private companies could be rewarded with tax exemptions if they employ a certain number of persons with disabilities. However, this should be accompanied with rigorous awareness creation on the capabilities of persons with disabilities among employers.

As access to education was limited for persons with disabilities in the area, it is important for the government to prioritize education for persons with disabilities. The government should ramp up efforts at introducing inclusive education so as to enable children with disabilities to enroll in schools in their respective communities. This will require investing in infrastructure and training teachers in special needs education. Additionally, the government should ratify the CRPD to make it an obligation for the government to refrain from any acts that violate the rights of persons with disabilities. Also, the study found that most persons with disabilities in the area were poor and unable to access essential services such as education and even healthcare. Therefore, it will be appropriate for the government to introduce some social welfare programs to cushion the effects of poverty on persons with disabilities in the area.

\section{Conclusions}

This study examined the situation of persons with disabilities living in the Buea Municipality 7 years after Cameroon signed the CRPD. The study found that persons with disabilities in the Buea Municipality faced many challenges in all aspects of life. They are unable to access essential services such as education, employment, and healthcare, suggesting that the impact of the CRPD is yet to be felt by persons with disabilities in the area. These findings are consistent with previous studies and portray a deep-seated insensitivity towards the concerns of persons with disabilities. It is, therefore, important for the government to implement provisions in the CRPD to increase the participation of persons with disabilities in mainstream society. In particular, the government should increase investment in the education for persons with disabilities to empower them to fight for their rights. As the sample for this study is limited to persons with disabilities in the Buea Municipality, it is important to conduct future studies in other regions to ascertain the living conditions of persons with disabilities across several communities in Cameroon. It is worth mentioning that despite the challenges persons with disabilities in the area were encountering, they appeared to have the ability to withstand adverse conditions and yearned to succeed. Their resilience to continue with life in the midst of social rejection, poverty, and limited access to essential services suggests that they are capable of succeeding if given some support.

Acknowledgments: We wish to thank the Institute of Governance, Humanities, and Social Science and the Centre for Disability Rehabilitation Studies for their support in the study. We also thank the Buea Municipal Council for their approval of the study. Our heartfelt gratitude goes to all the persons with disabilities who agreed to be part of the study.

\section{References}

1. International Labour Organization. Disability Inclusion strategy and action plan 2014-2017. A twin track approach of mainstreaming and disability specific actions. Geneva: International Labour Organization; 2015.

2. World Health Organization. World disability report. Geneva: WHO Press, 2011.

3. Mulumba M, Nantaba J, Brolan CE, Ruano AL, Brooker K, Hammonds R. Perceptions and experiences of access to public healthcare by people with disabilities and older people in Uganda. Int J Equity Health 2014;13:76.

4. Naami A. Disability, gender, and employment relationships in Africa: the case of Ghana. Afr J Disabil 2015;4:1-11.

5. Nyombi C, Kibandama A. Access to employment for persons with disabilities in Uganda. Labor Law J 2014;65:248-58.

6. Beresford B, Rhodes D. Housing and disabled children. York: Joseph Rowntree Foundation, 2008.

7. Filmer D. Disability, poverty, and schooling in developing countries: results from 14 household surveys. World Bank Econ Rev 2008;22:141-63.

8. Van Brakel WH. Measuring health-related stigma-a literature review. Psychol Health Med 2006;11:307-34.

9. O'Keefe Philip. People with disabilities in India: from commitments to outcomes. Washington, DC: World Bank, 2009. Available from 
http://documents.worldbank.org/curated/en/2009/07/11027298/ people-disabilities-india-commitments-outcomes.

10. Zaidi A, Burchardt T. Comparing incomes when needs differ: equalization for the extra costs of disability in the UK. Rev Income Wealth 2005;51:89-114.

11. Cullinan J, Gannon B, Lyons S. Estimating the extra cost of living for people with disabilities. Health Econ 2011;20:582-99.

12. Scheer J, Kroll T, Neri M, Beatty P. Access barriers for persons with disabilities: the consumer's perspective. J Disabil Policy Stud 2003;13:221-30.

13. Eide A, van Rooy G, Loeb M. Living Conditions among People with Activity Limitations in Namibia. A National Representative Survey, SINTEF Health Research, Oslo, Norway, 2003, http:// www.safod.org/Images/LCNamibia.pdf.

14. Eide A, Loeb M. Living Conditions among People with Activity Limitations in Zambia. A National Representative Study, SINTEF Health Research, Oslo, Norway, 2006. Available from http:// www.sintef.no/upload/Helse/Levek\%C3\%A5r\%20og\%20tjenester/ZambiaLCweb.pdf.

15. Mugimba C. ICT accessibility for PWDs in East African region: Uganda's country report. Paper presented at the ITU regional workshop on ICT accessibility for PWDs for the Africa region, Lusak, Zambia., Lusak, Zambia, 2008. https:// www.itu.int/ITU-D/sis/PwDs/Seminars/Zambia/Documents/ Presentations/028-Mugimba\%20Christine.pdf.

16. United Nations International Children's Fund. Promoting the Rights of Children with Disabilities, 2007. Available from http:// www.un.org/esa/socdev/unyin/documents/children_disability_rights.pdf.

17. Eide A, Kamaleri Y. Living Conditions among People with Disabilities in Mozambique. A National Representative Study, SINTEF Health Research, Oslo, Norway, 2009. http://www.sintef.no/ upload/Helse/Levekår\%20og\%20tjenester/LC\%20Report\%20 Mozambique\%20-\%202nd\%20revision.pdf.

18. Mitra S, Sambamoorthi U. Disability and the Rural Labor Market in India: Evidence for Males in Tamil Nadu, 2000. Available from http://citeseerx.ist.psu.edu/viewdoc/download?doi=10.1.1.476 $.6987 \&$ rep $=$ rep $1 \&$ type $=p d f$.

19. Hoogeveen JG. Measuring welfare for small but vulnerable groups: poverty and disability in Uganda. J Afr Econ 2005;14:603-31.

20. Loeb ME, Eide AH. Living conditions among people with activity limitations in Malawi: A national, representative study,
SINTEF report no. STF78 A044511, SINTEF Health Research, Oslo, 2004.

21. Rischewski D, Kuper H, Atijosan O, Lavy, C. Poverty and musculoskeletal impairment in Rwanda. Trans R Soc Trop Med Hyg 2008;102:608-17.

22. International Centre for Evidence in Disability. 2014. The North West Cameroon Disability Study Summary Report, London School of Hygiene and Tropical Medicine (LSHTM). Available from http://disabilitycentre.lshtm.ac.uk.

23. Cockburn L, Cleaver S, Benuh E. The prevalence of impairments and disabilities in the North West Region, Cameroon. Health Sci Dis 2014;15:1-7.

24. United Nations. Convention on the Rights of Persons with Disabilities, 2006. Retrieved from http://www.un.org/disabilities/ documents/convention/convoptprot-e.pdf.

25. Schulze M. Understanding the UN Convention on the Rights of Persons with Disabilities; September, 2009. Available from http://iddcconsortium.net/sites/default/files/resourcestools/ files/hi_crpd_manual_sept2009_final.pdf.

26. United Nations human rights commission. Breaking barriers to equal access to work for persons with disabilities, 2013. Available from http://www.ohchr.org/EN/NewsEvents/Pages/ Breakingbarrierstoequalaccessworkpersonswithdisabilities. aspx\#sthash.vMYdf5iz.dpuf.

27. Walker, J. The United Nations Convention on the rights of persons with disabilities: an overview. Library of Parliament: Ottawa; 2013. Available from www.parl.gc.ca/content/lop/ researchpublications/2013-09-e.pdf.

28. Eyong M. Implementing the UN Convention on the Rights of Persons with Disabilities in Africa: opportunities and challenges, 2011. Available from http://mdac.info/en/implementing-unconvention-rights-persons-disabili.

29. Ito N. Convention of the rights of persons with disabilities and perspectives of development assistance: a case study of Thai disability policy. Asia Pacific Disabil Rehabil J 2010;21.

30. McSweeney C, New M, Lizcano G, n.d. UNDP climate change country profile: Cameroon. Retrieved fromhttp://www.geog. ox.ac.uk/research/climate/projects/undp-cp/UNDP_reports/ Cameroon/Cameroon.lowres.report.pdf.

31. United councils and cities of Cameroon. Profile of Buea, 2014. Available from http://cvuc.cm/national/index.php/fr/carte-communale/region-du-sud/142-association/carte-administrative/ sud-ouest/fako/404-buea. 